\title{
Multifunctional Carbon Nanotubes Enhanced Structural Composites with Improved Toughness and Damage Monitoring
}

\author{
Colin Robert, Isabelle Pillin, Mickaël Castro and Jean-Francois Feller *(D) \\ Smart Plastics Group, University of South Brittany (UBS), IRDL CNRS 6027-UBS, 56321 Lorient, France; \\ colin_robert@yahoo.fr (C.R.); isabelle.pillin@univ-ubs.fr (I.P.); mickael.castro@univ-ubs.fr (M.C.) \\ * Correspondence: jean-francois.feller@univ-ubs.fr
}

Received: 3 October 2019; Accepted: 13 December 2019; Published: 17 December 2019

\begin{abstract}
The potential of carbon nanotubes (CNT) as multifunctional filler in poly(epoxy)-based structural composites has been investigated. In a first step the reinforcement effect of CNT has been studied by tensile and three points bending tests, which evidenced significant improvements of stress and strain at break (respectively $+17 \%$ and $+30 \%$ for tensile tests on unidirectional carbon fibre-epoxy composites). Moreover, fracture experiments have also revealed a positive effect of CNT on the toughness $\left(\mathrm{G}_{1 \mathrm{c}}\right)$ of carbon fibres-epoxy composites $(+105 \%$ of improvement at the initial stage). In a second step, the health monitoring capability quantum resistive strain sensors (sQRS) made of CNT filled epoxy nanocomposite, incorporated in the core of glass fibres-epoxy composites has been studied. It was shown that during cyclic tensile tests, following the evolution of the relative resistance amplitude $\left(\mathrm{A}_{\mathrm{r}}\right)$ of sQRS with strain gives a pertinent information on non-reversible phenomena such as plastic deformation and cracks' development within the composite. In particular, the evolution of the sQRS sensitivity (gauge factor GF) under and over the elastic limit, allows to track damage accumulation throughout the composite. These results suggest a possible use of sQRS for the structural health monitoring (SHM) of composites in fields such as boating, wind energy, aeronautics and automotive.
\end{abstract}

Keywords: fracture; toughness; Conductive Polymer nanoComposite; structural health monitoring; strain; damage accumulation; multi-walled carbon nanotube; carbon fiber; epoxy matrix; SHM

\section{Introduction}

Quite early after their popularization by lijma [1] in 1991, carbon nanotubes (CNTs) have raised hopes to improve polymers properties through the development of nanocomposites, due to their exceptional intrinsic properties [2-4]. In fact, the development of CNT nanocomposites has led to many applications in mechanics [5-8], electro-magnetic interference shielding [9], adhesion [10], detection [11-13], biomimetics [14], wearable [15], photonics [16], medicine [17], food [18] or energetics [19-21]. Nanocomposites can also be used to design smart materials [22-26], provided that a special attention is paid to the dispersion of nanofillers in the polymer matrix, and to their further structuring into stable conductive networks. If these conditions are fulfilled, the resulting Conductive Polymer nanoComposites (CPC) can meet many sensing applications for the detection of strain [27-31], temperature [32] and vapor [33-35].

Particularly in the boating, aeronautic, wind energy and automotive industries, the increasing use of structural composites have razed a need for the improvement of performances and the reliability of these materials. In this context CNTs have revealed to be promising multifunctional nanofillers, able to simultaneously enhance mechanical properties [36-40], monitor the strain [41-43] 
and predict the appearance of cracks [44-49], leading to SHM capability [50-52]. But the exceptional theoretical mechanical properties of CNTs resulting from a unique tubular configuration and $\mathrm{sp}^{2}$ carbon bounding [4], although confirmed experimentally on small bundles of CNTs [53-55], are hardly transferrable to the composite without deterioration. One cause is the tendency of CNTs to make bundles and aggregates due to their high specific surface and strong $\pi-\pi$ interactions, which decrease the modulus proportionally to their diameter, as shown by Salvetat et al. [56] by atomic force microscopy (AFM). This weakening can result from a sliding of the CNT due to the poor interfacial stress transfer in bundles, as evidenced by Ajayan et al. [57] by micro-Raman spectroscopy. Therefore, the improvement of epoxy resin's modulus and ultimate stress with CNT introduction requires a decrease of aggregates' size and number, as pointed out by Bai et al. [58]. This is of cause particularly true at high loadings, as CNTs are more likely to form aggregates. In such conditions, it is needful to use a high shearing dispersion tool such as a canlender [36,38], according to Gojny et al. [39] who increased the Young's modulus and the ultimate tensile strength of epoxy samples of respectively $15 \%$ and $8 \%$, with only $0.3 \%$ of amine-grafted, double-walled nanotubes. Moreover, CNTs were found to improve the fracture toughness of polymer matrices and interfacial shear strength between the matrix and the fiber [58-60]. Wagner et al. [61,62] using the Kelly-Tyson model, have estimated that the CNT, thanks to a surface area of 250 to $300 \mathrm{~m}^{2} \cdot \mathrm{g}^{-1}$, could increase the interfacial stress transfer up to $500 \mathrm{MPa}$, which is ten times more than in current advanced carbon fiber-reinforced composites (CFRC). The multifunctional character of carbon fillers in composites was evidenced early in the 1990s by Chung et al. [63], who investigated the fatigue behavior of carbon fibers/epoxy prepregs, by evaluating the fraction of broken carbon fibers from electrical measurements made during fatigue tests. Later on, the use of a 3D conductive network within the epoxy matrix to monitor the damage of glass fiber-reinforced composite (GFRC) was demonstrated by Chou et al. [41,45]. More recently, localized patches of conductive polymer nanocomposites were inserted in the core of composites made of epoxy reinforced with glass [48,51,52] and flax [64] fibers to design smart composites able to monitor structural health (SHM). The conductivity in CPC is mainly ruled by the tunneling effect, which is very sensitive to the evolution of the average gap between carbon fillers [65-68]. As reported, the tunneling conduction is cut off when the inter-particular distance between two adjacent CNT exceeds $1.8 \mathrm{~nm}$ [45]. This interesting feature allows the in situ measurement of strain and damage of the composite, and Chou et al. [45] showed that it was possible to model the appearance and the development of cracks during damage accumulation with a finite element method. Moreover, the nature of the electrical pattern during mechanical solicitations makes possible to distinguish between reversible elastic behavior, non-reversible plastic deformation and damage due to cracks ignition and propagation, validating the possibility of health monitoring [41-49].

In this work we have firstly investigated the ability of CNT to be used as reinforcing nanofiller in pure epoxy resin and in unidirectional (UD) carbon fiber/epoxy composites. To demonstrate this point, we see that tensile, three points bending and tenacity experiments have been done. Secondly, we have studied the multifunctional nature of CNT networks in glass fibers/epoxy composites, and in particular their potential to follow both strain and damage accumulation.

\section{Experimental}

\subsection{Materials}

Multiwall CNTs (NC7000) were kindly supplied by Nanocyl (Sambreville, Belgium). NC7000 have an average diameter and a length of about $9.5 \mathrm{~nm}$ and $1.5 \mu \mathrm{m}$, respectively, and possess a surface area comprised between 250 and $300 \mathrm{~m}^{2} \cdot \mathrm{g}^{-1}$. Diglycidyl ether of bisphenol A (Epolam 2020 ${ }^{\circledR}$ ) epoxy resin and 3-aminomethyl-3,5,5 trimethylcyclohexylamine hardener (see chemical formula in Figure 1) were provided by Axson (Chassieu, France). Taffetas E-glass fiber $\left(0^{\circ} / 90^{\circ}, 165 \mathrm{~g} \cdot \mathrm{m}^{-2}\right)$ were obtained from Gazechim Composites France (Béziers, France). 
<smiles>CC(C)(c1ccc(OCC2CO2)cc1)c1ccc(OCC2CO2)cc1</smiles>

(a)<smiles>CC1(C)CC(N)CC(C)(CN)C1</smiles>

(b)

Figure 1. Chemical formula of reactants of Epolam $2020^{\circledR}$ epoxy resin, (a) diglycidyl ether of bisphenol A, (b) 3-aminomethyl-3,5,5 trimethyl cyclohexyl amine.

\subsection{Fabrication}

Master batches of epoxy filled with $0.5 \mathrm{wt} \%$ and $1.5 \mathrm{wt} \%$ of NC $7000 \mathrm{CNT}$ were produced with a three-roll mills calender [22]. For the mechanical study, samples of epoxy (EP) and unidirectional carbon fibers (Toho Tenax with 800 Tex) reinforced epoxy composites (UDCF 62\%-EP 38\%) filled with $0 \mathrm{wt} \%$ and $0.5 \mathrm{wt} \%$ of CNT were prepared by contact stratification followed by compression under vacuum for tensile and three points bending characterizations. A roving with $\left[0^{\circ} ; 90^{\circ}\right]$ carbon fibers structure was used to investigate the interlaminar fracture toughness $\left(\mathrm{G}_{\mathrm{IC}}\right)$. For the health monitoring study, glass fibers-epoxy samples were also prepared by contact stratification. A layer of $60 \mu \mathrm{m}$ of $1.5 \mathrm{wt} \%$ CNT masterbatch was intercalated into the center of a glass fiber epoxy composite plate. This conductive layer was used as an in situ quantum resistive strain sensor (sQRS) [48] in these samples. The proportion of glass fiber was $55 \mathrm{wt} \%$. All samples were cured as described in technical data sheets of EPOLAM 2020 (from $25^{\circ} \mathrm{C}$ to $100{ }^{\circ} \mathrm{C}$ using isothermal of $2 \mathrm{~h}$ every $20^{\circ} \mathrm{C}$ ) [69].

\subsection{Characterization}

Tensile tests were performed according to the AFNOR T57 standard. Epoxy and UD carbon fibers/epoxy samples had an initial length of $250 \mathrm{~mm}$ and were tested at a speed rate of $1 \mathrm{~mm} \mathrm{~min}^{-1}$ with an extensometer, the length of which was $25 \mathrm{~mm}$. Three points bending tests were performed using the ISO 178 standard. The initial length of epoxy- and carbon fiber-reinforced epoxy samples were $80 \mathrm{~mm}$. The support span length was $60 \mathrm{~mm}$ and test speed was $1 \mathrm{~mm} \mathrm{~min}{ }^{-1}$. Experiments were performed in a room at controlled temperature $\left(23^{\circ} \mathrm{C}\right)$ and relative humidity $(46 \%)$.

The interlaminar fracture toughness $\left(\mathrm{G}_{\mathrm{IC}}\right)$ defined by Equation (1) was investigated using a double cantilever beam (DCB) test according the ASTM D5528 standard [70].

$$
G_{I c}=\frac{3 P \delta}{2 B(a+|\Delta|)}
$$

where $G_{I c}$ is the critical strain energy release rate, $P$ is the load, $\delta$ is the crosshead displacement, $B$ is the specimen width, $a$ is the crack length and $\Delta$ is a correction factor (according to the modified beam theory).

DCB samples had a length of $120 \mathrm{~mm}$ and were tested at a $1 \mathrm{~mm} \mathrm{~min}{ }^{-1}$ test speed rate as depicted in Figure 2. Notches were initiated in DCB samples by intercalating in their mid-plane a thin anti-adhesive PTFE (Teflon ${ }^{\circledR}$ ) film of different lengths. 


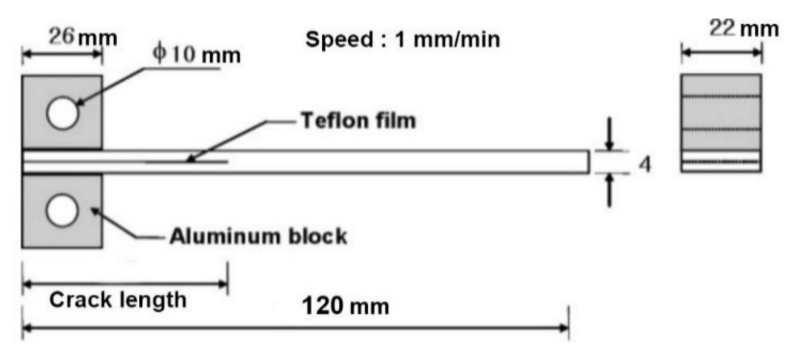

Figure 2. Scheme of double cantilever beam (DCB) samples with dimensions.

Glass fiber-reinforced epoxy samples had a length of $120 \mathrm{~mm}$. The sample thickness was $4 \mathrm{~mm}$ and the $1.5 \mathrm{wt} \% \mathrm{CNT}$ epoxy sensor thickness was $60 \mu \mathrm{m}$. Samples were tested at $0.2 \mathrm{~mm} \mathrm{~min}^{-1}$; the extensometer had a length of $10 \mathrm{~mm}$.

The mechanical tests were performed with an INSTRON 5566A (Instron, Elancourt, France) and an MTS Synergy RT/1000 (MTS Systems SAS, Créteil, France) tensile machine driven by TestWork (MTS Systems SAS, Créteil, France) and BlueHill (Instron, Elancourt, France) softwares, respectively.

The monitoring of the sQRS relative resistance amplitude variation was done by with a HIOKI 3522-50 LCR Hitester multimeter (Hioki, Nagano, Japan), and synchronized with strain measurements.

\section{Results \& Discussion}

\subsection{Effect of CNT on Stress, Strain and Modulus of EP Composites}

The effect of only $0.5 \mathrm{wt} \%$ of carbon nanotubes (CNTs) on the mechanical properties of both pure epoxy and UD-CF-reinforced epoxy have been investigated with tensile and three points bending tests. In order to better characterize the effect of interfaces, the UD samples were solicited in transverse mode, i.e., in the direction perpendicular to the main axis of their fibers. The impact of $0.5 \% \mathrm{CNT}$ on Young's modulus and the stress and strain of samples have been summarized in Table 1. In tension mode, only slight changes of the epoxy matrix mechanical properties are seen, the most important being an improvement of $4 \%$ of the stress at break for the addition of $0.5 \%$ CNT. These results are in good agreement with those obtained by Gojny et al. $[36,70,71]$ at similar concentrations with similar materials. Additionally, it is surprising to notice that only a small amount of CNT could degrade the epoxy's Young's modulus of $2 \%$. This could come from a significant increase of the viscosity, making less efficient the degassing of the matrix, and increasing the number of microvoids as assumed by Breton et al. [72].

Table 1. Summary of the evolution of mechanical properties of the epoxy matrix (EP) and the UD carbon fibers $62 \%$ /epoxy $38 \%$ (CF62/EP-38) composite due to the addition of $0.5 \%$ of carbon nanotubes (CNTs). Raw stress/strain data can be found in the supporting information part in Figures S1-S8 and Table S1 in Supplementary Materials.

\begin{tabular}{cccc}
\hline \multirow{2}{*}{ Type of Test } & Measured Parameter & (EP-0.5\% CNT)/EP & \{CF62/(EP-0.5CNT)37.5\}/[CF62/EP-38\} \\
\cline { 2 - 4 } & & (Longitudinal Mode) & (Transverse Mode) \\
\hline \multirow{3}{*}{ Tensile Test } & Young's modulus ratio (\%) & -2 & -18 \\
& Stress at break ratio (\%) & +4 & +15 \\
& Strain at break ratio (\%) & -3 & +30 \\
\hline \multirow{2}{*}{3 Points Bending } & Young's modulus ratio (\%) & +1 & -5 \\
Test & Stress at break ratio (\%) & +12 & +14 \\
& Strain at break ratio (\%) & +12 & +25 \\
\hline
\end{tabular}

The results of three points bending are showing that both stress and strain at break are improved of $15 \%$ in good agreement with the results of Nadler et al. [73] and Guo et al. [74], who found a 
similar improvement of stress and strain at break as well as a decrease in modulus of CFRC. A similar evolution was revealed by while increasing the CNT proportion in the epoxy matrix.

The improvements in mechanical properties may be explained by the ability of CNT to transfer the applied energy in the matrix and to decrease the interface stress concentration $[4,38,39,61,62,75,76]$. Godara et al. [77] investigated the influence of the transversal loading of carbon nanotube-reinforced UD-CFRC. They assumed that in this case, the failure was initiated within the matrix or at the fiber/matrix interface, and that the failure of the CNT/matrix phase would involve mechanisms such as bridging, slip through or partial debonding. Thus, the presence of CNT within the composite improved the ultimate tensile strain in transversal solicitation up to $+30 \%$ in the case of Godara et al. [72], which is similar to our result. This stress transfer ability of CNTs is due to their high aspect ratio combined with their important specific surface area. Delaminating and crack development effects along fiber are thereby decreased, and both stress and strain at break are increased. Higher energy transmission at the interface leads to higher ultimate tensile strain and decreases the Young's modulus [62]. Similar explanations about stress distribution within the matrix along transversal plies were given by Chou et al. [45] in a model representing damage sensing in an epoxy $\left[0^{\circ} / 90^{\circ}\right]$ cross-ply glass fiber composite embedded with a CNT network. The toughening effect of CNT at the interface for CFRC structures is a key point for mechanical enhancement and durability [39]. Additionally, a better repartition of stress tends to slow down damage mechanisms, such as crack appearance, development and delamination [76].

\subsection{Mode I Inter-Laminar Fracture Toughness}

The double cantilever beam (DCB) protocol allows one to evaluate the inter-laminar fracture toughness from the propagation of an existing crack. The largest stress concentration is located at the tip of the notch, between the central plies, and allows the crack development from this notch. Upon the application of a load to the sample, the crack propagates until the stress is partially released, which correspond to some intermediate equilibrium state, then an extra load will propagate the crack further step by step, until the complete breakage of the sample. The protocol allowing one to calculate $G_{I C}$ results from incremental jumps not causing sharp decreases in the load value [70] has explained in detail by Compston et al. [78]. The critical strain energy release rate, $G_{I c}$, was calculated using the corrected beam theory method (Equation (1)). A correction factor $\Delta$ needs to be added because of crack tip rotation at the root of the cantilever beam. This factor is the $\mathrm{x}$-axis intercept of the compliance cube $\operatorname{root} C^{1 / 3}$ as a function to crack length a.

Figure 3 represents the load deflexion curve of CNT-based carbon fiber-reinforced epoxy composite and carbon fiber-reinforced pristine epoxy composite DCB samples for cracks' initiation at different initial cracks' length. The general trend of the critical strain energy release represented by the solid curves was fitted to guide the eye thanks to a relationship between the energy and the initial crack distance for crack initiation, as used by Peters et al. for CFRC [79]. The stress required for CNT-based samples is much higher than for the based laminates, especially for small cracks propagation. In this study, an improvement of $25.6 \%$ of the $G_{I C}$ for $0.5 \mathrm{wt} \%$ CNT UD-EP samples upon neat samples was reported. Similar results $(+21 \%)$ were indicated by the Godara et al. investigation on UD-CFRC samples with the same CNT NC7000 from Nanocyl [77]. CNTs improve the interface interaction and the stress transfer between fiber and matrix, which leads to a material with a higher ultimate tensile strain [60].

Classically in thermoset, the resin's fracture toughness is enhanced by improving the interfacial adhesion between the hardener and the resin [77,80], or by adding a ratio of hyperbranched resin [81]. In both cases, it results in a higher deformation and enhances the fracture toughness of the composite. However, this approach reduces the modulus and the stress at the break of the composite [65]. Due to their very high specific surface area and aspect ratio, CNTs can improve the stress transfer between the resin and the fibers, thus leading to a decrease of the stress concentration between the laminate's layers [70]. Similar fracture behaviors between carbon nanotubes and carbon fibers in composites, showing pull out, CNT fracture, crack bridging [70] and stress-induced fragmentation of CNTs [62]. 


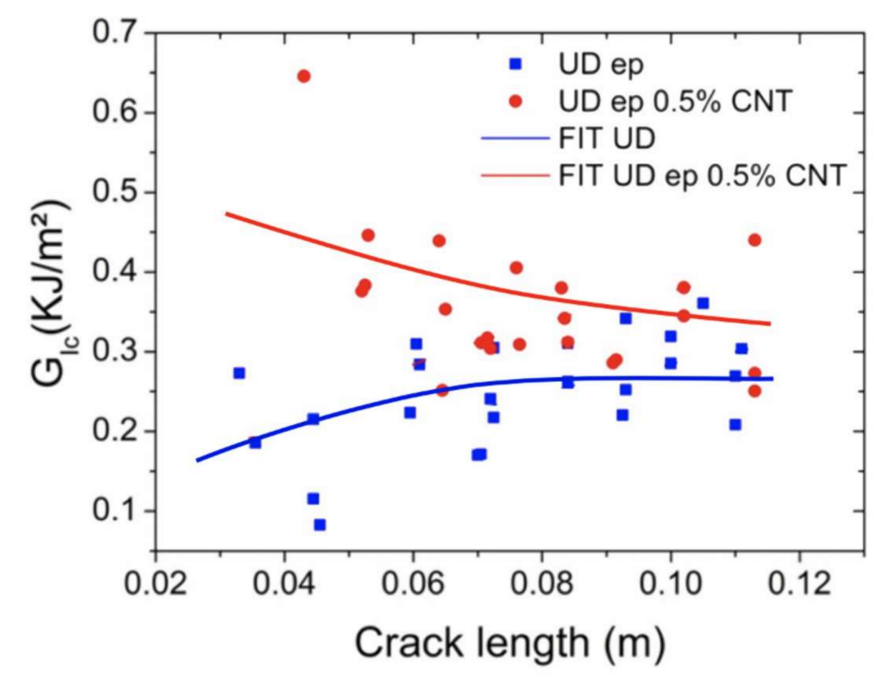

Figure 3. $G_{I c}$ Critical strain energy release initiation of carbon fiber reinforced epoxy with pristine epoxy and $0.5 \mathrm{wt} \%$ masterbatch.

The CNT-based epoxy matrix can store more energy during mechanical solicitation, especially when this energy is located in classical critical regions, at the interface between carbon fibers and CNT-based epoxy matrix. The addition of all these properties leads a major toughening role in CNT-based composites.

\subsection{Strain Sensing with CNT Based Nanocomposites}

To understand the opportunity given by CNTs to develop composite materials with a strain sensing capability, it is useful to come back to the origin of the conduction mechanisms in conductive nanocomposites. Knite et al. [67] have considered that the resistance in CNT-based nanocomposites was ruled by tunneling conduction, and could be expressed by Equation (2).

$$
R_{\text {total }}=\left(\frac{L}{N}\right)\left(\frac{8 \pi h s}{3 a^{2} \gamma e^{2}}\right) e^{\gamma s}
$$

where $R$ is the total resistance of the composite, $L$ is the number of particles forming a single conductive path, $N$ the number of conducting paths, $h$ the Planck's constant, $s$ the least distance between conductive particles, $a^{2}$ the effective cross-section where tunneling occurs, $e$ the electron charge, and $\gamma$ is calculated with Equation (3).

$$
\gamma=\frac{4 \pi(2 m \varphi)^{0.5}}{h}
$$

where $m$ is the electron mass and $\varphi$ the height of potential barrier between adjacent particles.

Schematically, the ability of electrons to circulate from a nanotube to the other at tunnel junctions requires that they can hop an energy potential barrier (quantum tunneling) when the interparticle distance " $s$ " is short enough (less than some nm). Thus, it can be understood from Figure 4 that considering the very large number of possible interconnections in random networks of entangled CNTs, and the wide distribution of the associated interparticle gaps, only a statistical approach, such as percolation theory, can be used. Under the percolation threshold no current can cross the material, but above, when enough connections can form sufficient conductive pathways, the polymer matrix can become conductive at the macroscopic scale. 


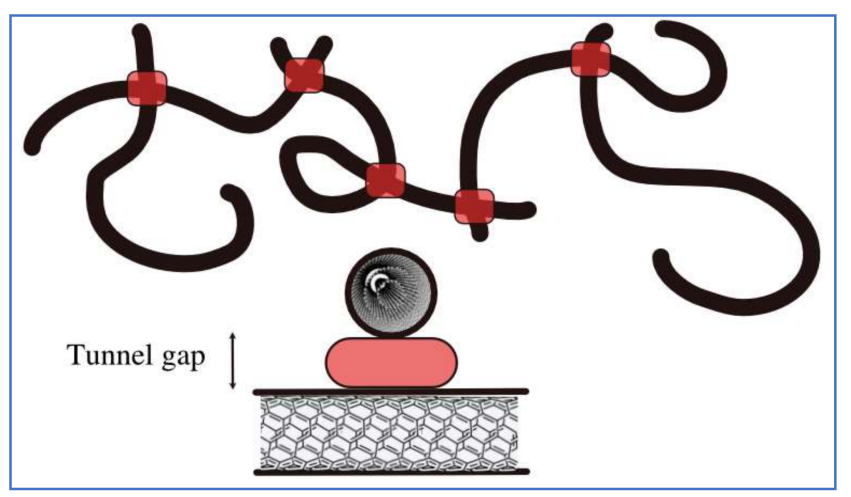

Figure 4. Schematic representation of the CNT-CNT junction's gap responsible for tunneling resistance in Conductive Polymer nanoComposites (CPC).

The conductivity of such material will therefore depend on the connections/disconnections of the numerous CNT-forming conductive pathways $(L)$, on the number of effective paths $(N)$ and the average least distance between particles, according to Equation (4). It can be seen that the evolution of this distance $s$ leads to an exponential relationship between relative gap and the relative resistance.

$$
\frac{R}{R_{0}}=\left(\frac{s}{s_{0}}\right) e^{\gamma\left(s-s_{0}\right)}
$$

where $R_{0}$ is the initial resistance, and $s_{0}$ the initial interparticle length.

Interestingly, any variation of the environmental parameters of the conducting nanocomposite able to change its interparticle length " $s$ ", such as stress, temperature or chemicals, will trigger an exponential variation of resistance, opening the way to the design of smart materials. After connection to a suitable device, recording the evolution of $\Delta R / R_{0}$ of such materials will thus allow one to monitor their strain and eventual degradation. This evolution also represents the sensitivity of the sensor, called $A_{r}$ for relative amplitude resistance, as shown in the equation below:

$$
A_{r}=\frac{R-R_{0}}{R_{0}}
$$

where $R$ is the resistance at a given moment and $R_{0}$ is the initial resistance, both in ohms.

\subsection{Damage Accumulation Monitoring}

The appearance of damage in structural composites is generally located at the interface between the matrix and the reinforcing textile or between plies. The development of the cracks is then induced by a stress concentration and a preferential orientation mechanism toward the fibers, which leads to delamination and finally the fibers' breakage. To avoid such catastrophic failure, it is then crucial to detect the damage at an early stage, throughout crack appearance and development.

An attempt to quantify the damage evolution was performed by Thostenson et al. on glass fiber epoxy-CNT $0.5 \mathrm{wt} \%$ composites with a gradual tensile profile [82]. An exponential drift of the relative resistance amplitude $\left(A_{r}\right)$ was observed at each cycle. Also, a relative resistance amplitude hysteresis between loading and unloading for high stresses was reported. Similar studies from Böger et al. [83] reported the appearance of residual strain in a cyclic incremental strain tensile profile after a threshold value. They assumed this residual strain can be attributed to plastic deformation and damage appearance within the matrix transversal layers [84]. 
During a mechanical solicitation, the structure of the CNT conductive network is modified by cracks appearance and development. Some electrical paths are permanently destroyed, resulting in an irreversible resistance increase. In this analysis, incremental tensile loading cycles were applied to glass fibers-reinforced epoxy laminates to investigate the damage accumulation occurring within the composite. Figure 5 represents the evolution of stress during an incremental loading, of the stress imposed to a glass fiber reinforced epoxy with a $1.5 \mathrm{wt} \%$ CNT sample, as well as the resulting strain measured by the tensile testing equipment and the relative resistance amplitude of an integrated quantum resistive strain sensor (sQRS) measured by a multimeter.

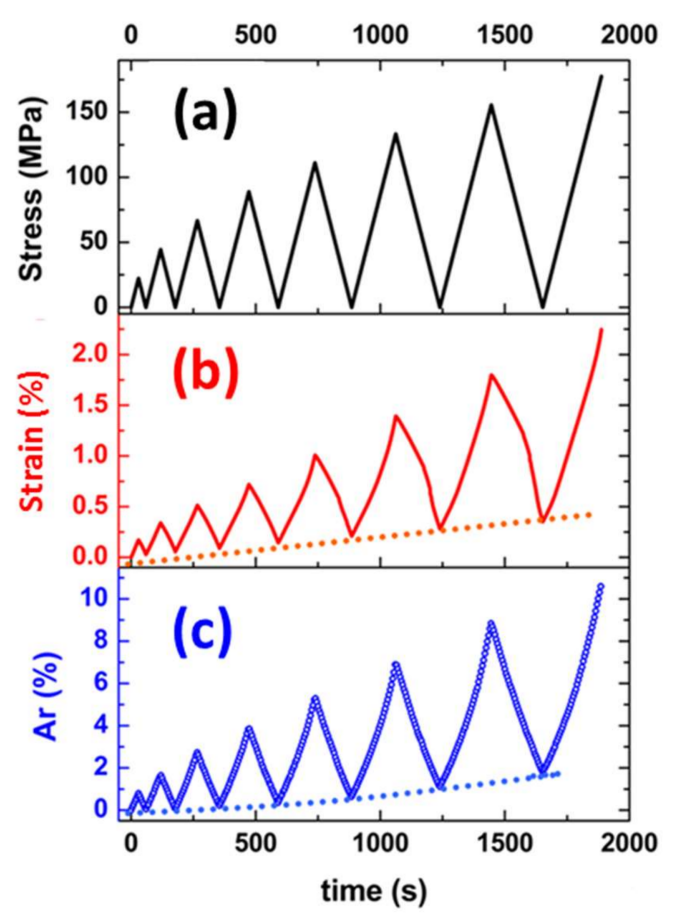

Figure 5. (a) stress $(\delta)$, (b) strain $(\varepsilon)$ and (c) relative resistance amplitude $\left(A_{r}\right)$ evolution versus time, during the cyclic solicitation of glass fiber-reinforced epoxy with a $1.5 \mathrm{wt} \% \mathrm{CNT}$ in situ strain sensor.

At first sight, the relative resistance amplitude and the strain seem to well follow the stress solicitation. However, a finer analysis of the curves shows that both the strain and the piezo-resistive response plots evidence a linear drift in their base line (dashed line) and a hysteresis between loading and unloading appearing at high stresses and characterized by nonlinear features. This evolution is attributed to the appearance of breakages in the polymer chains $[41,82,83]$. This is also well visualized in Figure 6a, in which the evolution of $A_{r}$ versus the strain of glass fiber-reinforced epoxy with $1.5 \mathrm{wt} \%$ CNT instrumented with an in-situ sQRS, under incremental stress, is represented.

Comparing Figure $6 \mathrm{a}, \mathrm{b}$ shows that the damage accumulation within the matrix is well featured by the sensor and highlighted by the tangential dashed lines at the third and seventh cycle. According to Lachman et al. [85], this evolution could also be associated to the development of cracks throughout the epoxy matrix, destroying at the same time some electrical pathways, highlighted by the $A_{r}$ drift, when the stress is completely released at each of the consecutive cycles in Figure 5. 

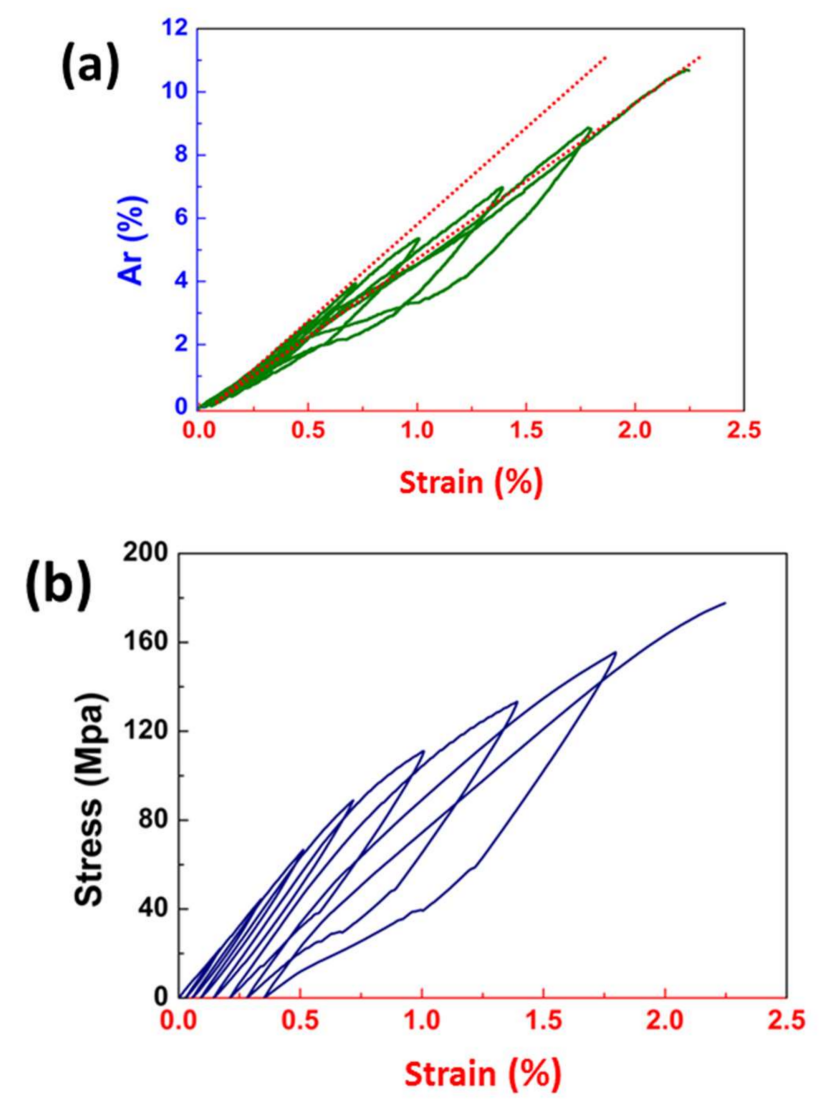

Figure 6. (a) In the upper graph, a relative amplitude resistance versus strain evolution of glass fiber-reinforced epoxy with $1.5 \mathrm{wt} \% \mathrm{CNT}$ in situ strain sensor with increment stress. The tangential dashed lines represent the sensitivity at the third and seventh cycle during load. (b) In the lower graph, a stress versus strain evolution of glass fiber-reinforced epoxy with $1.5 \mathrm{wt} \% \mathrm{CNT}$ in situ strain sensor with incremental stress.

Moreover, from the mechanical point of view, the appearance of defects is affecting the composite's mechanical integrity, inducing non-reversible strain (Figure 6b). On cycles 4 to 7 in Figure 6a, one can notice a hysteresis during unloading, assumed by Thostenson et al. [41,46] to act as a witness of damage propagation. Therefore, it can be concluded that the trace of $A_{r}$ versus $\varepsilon$ gives a pertinent visualization of the increase of crack density with the number and intensity of loading cycles. The two dashed lines plotted in Figure 6a at cycles 3 and 7 feature the decrease in sensitivity of the sQRS during cycling, as these tangents correspond to the gauge factor GF. Another representation of the same phenomenon is given in Figure 7 where the residual relative resistance amplitude $\left(A_{r}\right)$ at the end of each cycle is plotted versus the residual strain, at complete unloading. Such exponential increase of $A_{r}$ with strain has been ascribed by some authors to the disconnection of the CNT network during a plastic deformation process [86-88]. Moreover, the exponential evolution of the piezo-resistive response with strain at high loadings is also characteristic of the percolated structure's degradation, due to the increase of cracks density and damage propagation [46]. This also means that the electrical measurement is more effective to characterize the damage accumulation than the mechanical one. 


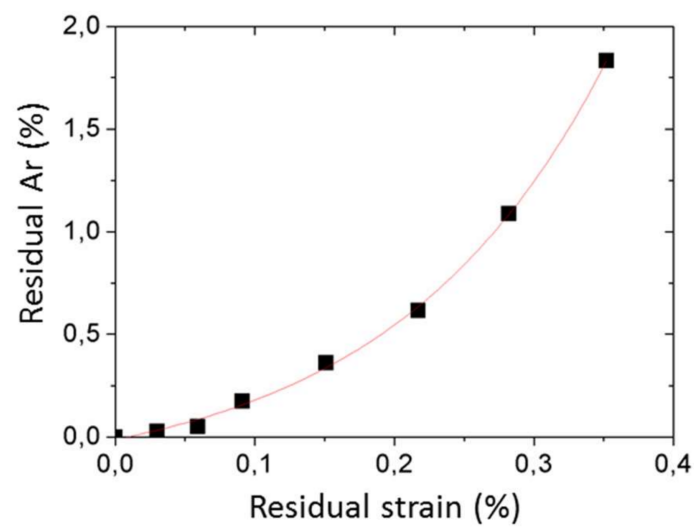

Figure 7. Hysteresis characterized by the evolution of residual $A_{r}$ at the end of each cycle from Figure 6a versus the residual strain evidencing the damage evolution in glass fiber-reinforced epoxy with an EP 1.5 wt \% CNT in situ strain sensor.

At high loads, the sample is strongly solicited inside the epoxy matrix and along the reinforcing glass fibers. Then, the non-linear strain behavior during unloading can be separated into two steps. In the first step, a release of energy occurs in stress concentration areas, at cracks locations visible on Figure $6 \mathrm{~b}$; in a second step, the linear strain decrease compared to stress indicates the entrance in an elastic domain.

The area below a stress-strain curve (Figure 6b) represents the elastic energy per unit volume stored by the composite. The exponential increase of hysteresis, which is the area ratio between loading and unloading at each cycle plotted in Figure 8. This ratio represents the energy loss and suggests that the release of energy within the polymer matrix is mainly due to increasing crack concentration.

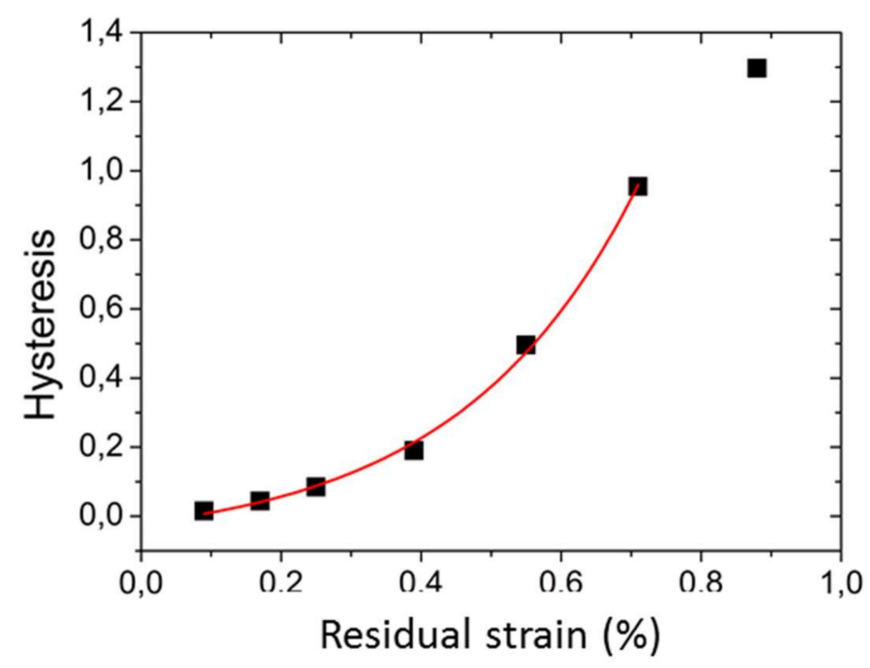

Figure 8. Hysteresis characterized by the evolution of the area below a stress-strain curve in Figure $6 \mathrm{~b}$ versus residual strain.

Chou et al. analyzed this increase of weakness of the composite with damage accumulation with a finite element approach in $\left[0^{\circ} / 90^{\circ}\right]$ cross-ply glass fiber/CNT-based epoxy composites [45], and proposed a model describing this phenomenon while assuming that stress concentration acts mainly on the longitudinal matrix along carbon fibers at small deformation in a unidirectional tensile experiment. Then cracks propagate in the transverse direction along fibers. In this simulation, local stress concentration at the interface with the matrix leads to high strain between adjacent nanotubes, 
and results in the appearance of microcracks, which is irreversibly damaging the conductive network. Above $0.5 \%$ strain, cracks are appearing and lead to a dramatic rise of the resistance as seen in Figure 8.

The gauge factor (GF) determined from each loading and calculated from Equation (6) is plotted versus the number of loading cycles in Figure 9. It can be seen that GF behaves differently in the elastic range of strain (1), and in the plastic range (2). This provides an interesting way to follow the damage phenomenon described above, i.e., using the transition between elastic and non-recoverable strain to eventually anticipate the damage.

$$
G F=\frac{\Delta A_{r}}{\Delta \epsilon}
$$

Calculation of the gauge factor: where GF is the gauge factor, $\Delta A_{r}$ is the difference between $A_{r}$ when the stress is maximal minus $A_{r}$ at unload for each cycle and $\Delta \varepsilon$ is the maximal strain minus the remaining strain at unload for each cycle.

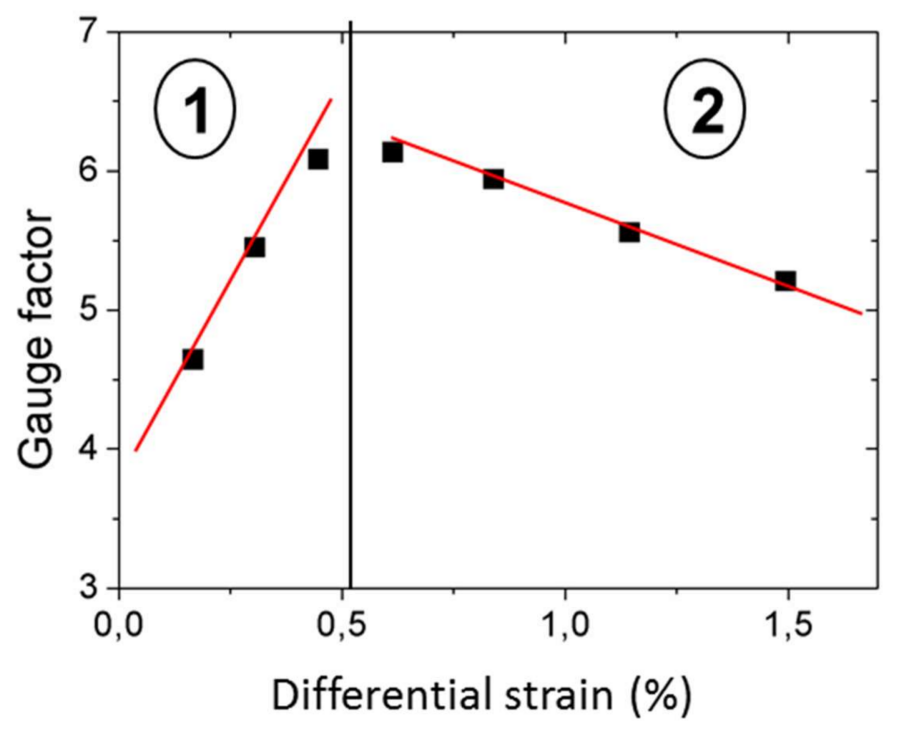

Figure 9. Influence of load and damage on the gauge factor of glass fiber-reinforced epoxy with a $1.5 \mathrm{wt} \% \mathrm{CNT}$ in situ strain sensor (sQRS).

It can be noticed that during the three first cycles, the response of the sQRS is stable despite that a slight remnant strain occurs (Figure 7). Over the third cycle, as in the simulation of Chou et al., the strain concentration initially localized at the interface between the fibers and CNT, is affecting the matrix incrementally. Although this reversible process has little effect on the sensor structural integrity, it resulted in an increase of its sensitivity for larger strains. The strain concentration increased the CNT interparticle distance between CNTs, making electron tunneling less probable, which led to progressive disconnection of conductive pathways and finally to an exponentially growing sensor sensitivity to macroscopic strain.

On Figure 9, it is clearly visible that the sensitivity, represented by the gauge factor, rises by $31 \%$ for $0.45 \%$ strain against only $0.17 \%$ strain at the first cycle.

Over the elastic deformation limit, the GF decreased with increasing loading. However, it should be noticed that in this study, the gauge factor was calculated from the initial part of the curve for each cycle, in the elastic domain. A careful observer can notice a sharp slope at the end of the high stress cycles in Figure 5c. On the unloading steps, the opposite trend takes place, as the slope is initially sharp and became gradually smoother. But this rather symmetrical behavior of $A_{r}$ is not observed on the mechanical trace in Figure 5b. It is believed that in this later case, the elastic recovery appends first, followed by the non-linear contribution of higher negative slope. In this study, it has been shown that the appearance and development of cracks, and the gradual weakening of the matrix due internal 
stresses can well be monitored from both a mechanical and an electrical point of view, but that this phenomenon is not exactly transduced in the same way.

\section{Conclusions}

The objective of the paper was to investigate the multifunctional capability of carbon nanotubes when dispersed in a poly(epoxy) matrix. In a first part our results allowed us to show that the enhanced stress transfer ability of CNTs can improve the ultimate tensile strength and strain in traction and flexion of both bulk epoxy and UD carbon fiber laminates. However, a slight decrease of Young's modulus was also noticed. The benefit of CNT was found larger in structural carbon fibers composites than in bulk epoxy, suggesting that CNTs are improving the stress transfer from carbon fiber to the epoxy resin. In a second part the potential of CNT to design core sensors for strain and damage accumulation monitoring has been established in advanced laminate composites. The evolution of the strain during tensile solicitations can be monitored with a local CNT conductive network intercalated between plies. The behavior of the composite may be described in two states. Before the massive appearance of cracks, the sensor's sensitivity (GF) is driven by the evolution of the tunneling distance and electrical pathway disconnection of the CNT network. GF is enhanced thanks to the more heterogeneous distribution of strain and orientation phenomena promoting anisotropy, which becomes more important at higher loads. Under this reversible process, the conductivity of the sensor remains stable from a cycle to the other.

Then, over the elastic limit, damage accumulation and cracks development can be identified and quantified through the exponential evolution of $A_{r}$ with the remnant strain after each mechanical cycle. The apparent decrease of the sensitivity of sensors noticed is also a witness of the damage evolution within the composite.

Therefore, it can be concluded that carbon nanotubes can provide composites with both enhanced strength and heath monitoring capability, but not necessary at the same location and content in the polymer matrix.

Supplementary Materials: The following are available online at http://www.mdpi.com/2504-477X/3/4/109/s1. Raw data of stress/strain experiments with pure EP, EP-CNT, UD GF-EP and UD GF-EP-CNT are summarized in Table S1 from the analysis of the curves plotted in Figures S1-S8.

Author Contributions: I.P. and C.R. did respectively the experimental work, on mechanical and electrical characterization, M.C. has supervised the realization of the tasks and J.-F.F. managed the whole project, all authors have contributed to the redaction at their level.

Funding: Brittany Region \& General Council of Morbihan.

Acknowledgments: This work was part of the Smart2Ship project. We are also grateful to Hervé Béllégou \& Anthony Magueresse from UBS and Magali Coulaud \& Frédéric Luizi from Nanocyl S.A. for their contributions to this work.

Conflicts of Interest: The authors declare no conflict of interest

\section{References}

1. Iijima, S. Helical microtubules of graphitic carbon, Nature 1991, 354, 56-58. Nature 1991, 354, 56-58. [CrossRef]

2. Ajayan, P.M.; Stephan, O.; Colliex, C.; Trauth, D. Aligned carbon nanotube arrays formed by cutting a polymer resin-nanotube composite. Science 1994, 265, 1212-1214. [CrossRef] [PubMed]

3. Calvert, P. A recipe for strength. Nature 1999, 399, 210-211. [CrossRef]

4. Salvetat, J.P.; Bonard, J.M.; Thomson, N.H.; Kulik, A.J.; Forro, L.; Benoit, W.; Zuppiroli, L. Mechanical properties of carbon nanotubes. Appl. Phys. A 1999, 69, 255-260. [CrossRef]

5. Thostenson, E.T.; Ren, Z.; Chou, T.W. Advances in the science and technology of carbon nanotubes and their composites: A review. Compos. Sci. Technol. 2001, 61, 1899-1912. [CrossRef]

6. Coleman, J.N.; Khan, U.; Blau, W.J.; Gun'ko, Y.K. Small but strong: A review of the mechanical properties of carbon nanotube-polymer composites. Carbon 2006, 44, 1624-1652. [CrossRef] 
7. Yang, B.X.; Pramoda, K.P.; Xu, G.Q.; Goh, S.H. Mechanical reinforcement of polyethylene using polyethylene-grafted multiwalled carbon nanotubes. Adv. Funct. Mater. 2007, 17, 2062-2069. [CrossRef]

8. Gawryla, M.D.; Liu, L.; Grunlan, J.C.; Schiraldi, D.A. PH tailoring electrical and mechanical behavior of polymer-clay-nanotube aerogels. Macromol. Rapid Commun. 2009, 30, 1669-1673. [CrossRef]

9. Park, K.Y.; Lee, S.E.; Kim, C.G.; Han, J.H. Application of CNT-added glass fabric/epoxy composites to electromagnetic wave shielding enclosures. Compos. Struct. 2007, 81, 401-407. [CrossRef]

10. Qu, L.; Dai, L. Gecko-foot-mimetic aligned single-walled carbon nanotube dry adhesives with unique electrical and thermal properties. Adv. Mater. 2007, 19, 3844-3849. [CrossRef]

11. Villmow, T.; John, A.; Pötschke, P.; Heinrich, G. Polymer/carbon nanotube composites for liquid sensing: Selectivity against different solvents. Polymer 2012, 53, 2908-2918. [CrossRef]

12. Zhang, R.; Dowden, A.; Deng, H.; Baxendale, M.; Peijs, T. Conductive network formation in the melt of carbon nanotube/thermoplastic polyurethane composite. Compos. Sci. Technol. 2009, 69, 1499-1504. [CrossRef]

13. Laquintinie, P.S.; Sachan, A.; Feller, J.F.; Lahuec, C.; Castro, M.; Seguin, F.; Dupont, L. An electronic nose prototype for the on-field detection of nerve agents. IEEE Sens. 2018, 1-4. [CrossRef]

14. Kim, Y.; Chortos, A.; Xu, W.; Liu, Y.; Oh, J.Y.; Son, D.; Kang, J.; Foudeh, A.M.; Zhu, C.; Lee, Y.; et al. A bioinspired flexible organic artificial afferent nerve. Science 2018, 360, 998-1003. [CrossRef] [PubMed]

15. Zhou, X.; Zhu, L.; Fan, L.; Deng, H.; Fu, Q. Fabrication of highly stretchable, washable, wearable, water-repellent strain sensors with multi-stimuli sensing ability. Acs Appl. Mater. Interfaces 2018, 10, 31655-31663. [CrossRef] [PubMed]

16. Terrones, M. Science and technology of the twenty first century: Synthesis, properties, and applications of carbon nanotubes. Ann. Rev. Mater. Res. 2003, 33, 419-501. [CrossRef]

17. Kim, D.H.; Lu, N.; Ma, R.; Kim, Y.S.; Kim, R.H.; Wang, S.; Wu, J.; Won, S.M.; Tao, H.; Islam, A.; et al. Epidermal Electronics. Science 2011, 333, 838-843. [CrossRef]

18. Schroeder, V.; Evans, E.D.; Wu YC, M.; Voll CC, A.; McDonald, B.R.; Savagatrup, S.; Swager, T.M. Chemiresistive sensor array and machine learning classification of food. ACS Sens. 2019, 4, 2101-2108. [CrossRef]

19. Fang, Y.; Zhao, J.; Zha, J.W.; Wang, D.R.; Dang, Z.M. Improved stability of volume resistivity in carbon black/ethylene-vinyl acetate copolymer composites by employing multi-walled carbon nanotubes as second filler. Polymer 2012, 53, 4871-4878. [CrossRef]

20. Kim, D.; Kim, Y.; Choi, K.; Grunlan, J.C.; Yu, C. Improved thermoelectric behavior of nanotube-filled polymer composites with poly(3,4-ethylene dioxythiophene) poly(styrene sulfonate). ACS Nano 2010, 4, 513-523. [CrossRef]

21. Antar, Z.; Feller, J.F.; Noël, H.; Glouannec, P.; Elleuch, K. Thermoelectric behaviour of melt processed carbon nanotube/graphite/poly(lactic acid) conductive biopolymer nanocomposites (CPC). Mater. Lett. 2012, 67, 210-214. [CrossRef]

22. Dai, L. Intelligent Macromolecules for Smart Devices: From Materials Synthesis to Device Applications 2004; Springer: London, UK, 2004; pp. 1-496.

23. Varadan, V.K.; Vinoy, K.J.; Gopalakrishnan, S. Smart Material Systems \& MEMS: Design E Development Methodologies; John Wiley \& Sons: Chichester, UK, 2006; pp. 1-404.

24. Kang, I.; Heung, Y.Y.; Kim, J.H.; Lee, J.W.; Gollapudi, R.; Subramaniam, S.; Narasimhadevara, S.; Hurd, D.; Kirikera, G.R.; Shanov, V.; et al. Introduction to carbon nanotube and nanofibre smart materials. Compos. B Eng. 2006, 37, 382-394. [CrossRef]

25. Feller, J.F.; Castro, M.; Kumar, B. Polymer carbon nanotube conductive nanocomposites for sensing. In Polymer Carbon Nanotube Composites: Preparation, Properties and Applications; McNally, T., Pötschke, P., Eds.; Woodhead Publishing: Cambridge, UK, 2011; pp. 760-803.

26. Feller, J.F. 6.10 Electrically Conductive Nanocomposites. In Comprehensive. Composite Materials II, 2nd ed.; Beaumont, P.W.R., Zweben, C.H., Eds.; Elsevier: Amsterdam, The Netherlands, 2018; pp. 248-314.

27. Yamada, T.; Hayamizu, Y.; Yamamoto, Y.; Yomogida, Y.; Izadi-Najafabadi, A.; Futuba, D.N.; Hata, K. A stretchable carbon nanotube strain sensor for human-motion detection. Nat. Nanotechnol. 2011, 6, $296-301$. [CrossRef] [PubMed]

28. Lipomi, D.J.; Vosgueritchian, M.; Tee BC, K.; Hellstrom, S.L.; Lee, J.; Fox, C.H.; Bao, Z. Skin-like pressure and strain sensors based on transparent elastic films of carbon nanotubes. Nat. Nanotechnol. 2011, 6, 788-792. [CrossRef] [PubMed] 
29. Robert, C.; Feller, J.F.; Castro, M. Sensing skin for strain monitoring made of PC-CNT conductive polymer nanocomposite sprayed layer by layer. ACS Appl. Mater. Interfaces 2012, 4, 3508-3516. [CrossRef]

30. Zhang, R.; Deng, H.; Valenca, R.; Jin, J.; Fu, Q.; Bilotti, E.; Peijs, T. Strain sensing behaviour of elastomeric composite films containing carbon nanotubes under cyclic loading. Compos. Sci. Technol. 2013, 74, 1-5. [CrossRef]

31. Zhao, H.; Bai, J. Highly sensitive piezo-resistive graphite nanoplatelet-carbon nanotube hybrids/polydimethylsilicone composites with improved conductive network construction. ACS Appl. Mater Interfaces 2015, 7, 9652-9659. [CrossRef]

32. Lu, J.; Castro, M.; Feller, J.F. Thermo- and chemo-electrical behaviour of carbon nanotube filled co-continuous conductive polymer nanocomposites (CPC) to develop amperometric sensors. Mater. Res. Soc. Symp. Proc. 2009, 1143E. [CrossRef]

33. Kumar, B.; Castro, M.; Feller, J.F. Poly(lactic acid)-multiwall nanotube conductive biopolymer nanocomposite vapour sensors. Sens. Actuators B Chem. 2012, 161, 621-628. [CrossRef]

34. Kumar, B.; Feller, J.F.; Castro, M.; Lu, J. Conductive bio-polymer nano-composites (CPC): Chitosan-carbon nanotube transducers assembled via spray layer-by-layer for volatile organic compound sensing. Talanta 2010, 81, 908-915. [CrossRef]

35. Lu, J.; Park, B.J.; Kumar, B.; Castro, M.; Choi, H.J.; Feller, J.F. Polyaniline nanoparticle-carbon nanotube hybrid network vapour sensors with switchable chemo-electrical polarity. Nanotechnology 2010, 21, 255501. [CrossRef] [PubMed]

36. Spitalsky, Z.; Tasi, D.; Papgelis, K.; Galioti, C. Carbon nanotube-polymer composites: Chemistry, processing mechanical and electrical properties. Prog. Polym. Sci. 2010, 35, 357-401. [CrossRef]

37. Gojny, F.H.; Wichmann MH, G.; Kopke, U.; Fiedler, B.; Schulte, K. Carbon nanotube-reinforced epoxy composites: Enhanced stiffness and fracture toughness at low nanotube content. Compos. Sci. Technol. 2004, 64, 2363-2371. [CrossRef]

38. Thostenson, E.T.; Ziaee, S.; Chou, T.W. Processing and electrical properties of carbon nanotube/vinyl ester nanocomposites. Compos. Sci. Technol. 2009, 69, 801-804. [CrossRef]

39. Gojny, F.H.; Wichmann MH, G.; Fielder, B.; Schulte, K. Influence of different carbon nanotubes on the mechanical properties of epoxy matrix composites-A comparative study. Compos. Sci. Technol. 2005, 65, 2300-2313. [CrossRef]

40. Gojny, F.H.; Wichmann MH, G.; Fielder, B.; Schulte, K. Influence of nano-modification on the mechanical and electrical properties of conventional fibre-reinforced matrix. Compos. Part A 2005, 36, 1525-1535. [CrossRef]

41. Zhao, Q.; Wagner, H.D. Two-dimensional strain mapping in model fibre-polymer composites using nanotube Raman sensing. Compos. A Appl. Sci. Manuf. 2003, 34, 1219-1225. [CrossRef]

42. Pham, G.T.; Park, Y.B.; Liang, Z.; Zhang, C.; Wang, B. Processing and modelling of conductive thermoplastic/carbon nanotube films for strain sensing. Compos. B Eng. 2008, 39, 209-216. [CrossRef]

43. De la Vega, A.; Kinloch, I.A.; Young, R.J.; Bauhofer, W.; Schulte, K. Simultaneous global and local strain sensing in SWCNT-Epoxy composites by Raman and impedance spectroscopy. Compos. Sci. Technol. 2011, 71, 160-166. [CrossRef]

44. Thostenson, E.T.; Chou, T.W. Real-time in situ sensing of damage evolution in advanced fibre composites. Nanotechnology 2008, 19, 215713. [CrossRef]

45. Li, C.; Chou, T.W. Modeling of damage sensing fibre composites using carbon nanotube networks. Compos. Sci. Technol. 2008, 68, 3373-3379. [CrossRef]

46. Gao, L.; Thostenson, E.T.; Zhang, Z.; Chou, T.W. Sensing of damage mechanism in fibre-reinforced composite under cyclic loading using carbon nanotubes. Adv. Funct. Mater. 2009, 19, 123-130. [CrossRef]

47. Abot, J.L.; Song, Y.; Vatsavaya, M.S.; Medikonda, S.; Kier, Z.; Jayasinghe, C.; Rooy, N.; Shanov, V.N.; Schulz, M.J. Delamination detection with carbon nanotube thread in self-sensing composite materials. Compos. Sci. Technol. 2010, 70, 1113-1119. [CrossRef]

48. Nag-Chowdhury, S.; Bellegou, H.; Pillin, I.; Castro, M.; Longrais, P.; Feller, J.F. Interfacial nanocomposite sensors (sQRS) for the core monitoring of polymer composites' fatigue and damage analysis. NanoComposites 2018, 4(3), 69-79. [CrossRef]

49. Chou, T.W.; Gao, L.; Thostenson, E.T.; Zhang, Z.; Byun, J.H. An assessment of the science and technology of carbon nanotube-based fibres and composites. Compos. Sci. Technol. 2010, 70, 1-19. [CrossRef] 
50. Zhang, H.; Bilotti, E.; Peijs, T. The use of carbon nanotubes for damage sensing and structural health monitoring in laminated composites: A review. NanoComposites 2016, 4, 167-184. [CrossRef]

51. Nag-Chowdhury, S.; Bellegou, H.; Pillin, I.; Castro, M.; Longrais, P.; Feller, J.F. Non-intrusive health monitoring of infused composites with embedded carbon quantum piezo-resistive sensors. Compos. Sci. Technol. 2016, 123, 286-294. [CrossRef]

52. Kumar, S.; Falzon, B.G.; Hawkins, S.C. Ultrasensitive embedded sensor for composite joints based on a highly aligned carbon nanotube web. Carbon 2019, 149, 380-389. [CrossRef]

53. Arinstein, A.; Burman, M.; Gendelman, O.; Zussman, E. Effect of supramolecular structure on polymer nanotube elasticity. Nat. Nanotechnol. 2007, 2, 59-62. [CrossRef]

54. Sui, X.; Wagner, H.D. Tough nanocomposites: The role of carbon nanotube type. Nano Lett. 2009, 9, 1423-1426. [CrossRef]

55. Cuenot, S.; Fretigny, C.; Demoustier-Campagne, S.; Nysten, B. Measurement of elastic modulus of nanotubes by resonant contact atomic force microscopy. J. Appl. Phys. 2003, 9, 5650-5655. [CrossRef]

56. Salvetat, J.P.; Briggs GA, D.; Bonard, J.M.; Basca, R.R.; Kulik, A.J.; Stockli, T. Elastic and shear moduli of single walled nanotube ropes. Phys. Rev. Lett. 1999, 82, 944-947. [CrossRef]

57. Ajayan, P.M.; Schadler, L.S.; Giannaris, C.; Rubio, A. Single-walled nanotube-polymer composites: Strength and weaknesses. Adv. Mater. 2000, 12, 750-753. [CrossRef]

58. Bai, J.B.; Allaoui, A. Effect of the length and the aggregate size of MWNTs on the improvement efficiency of the mechanical and electrical properties of nanocomposites-experimental investigation. Composites A 2003, 34, 689-694. [CrossRef]

59. Sager, R.J.; Klein, P.J.; Lagoudas, D.C.; Zhang, Q.; Liu, J.; Dai, L.; Baur, J.W. Effect of carbon nanotubes on the interfacial shear strength of T650 carbon fibre in an epoxy matrix. Compos. Sci. Technol. 2009, 69, 898-904. [CrossRef]

60. Keeple, K.L.; Sanborn, G.P.; Lacasse, P.A.; Gruenberg, K.M.; Ready, W.J. Improved fracture toughness of carbon fibre composite functionalized with multi walled carbon nanotubes. Carbon 2008, 46, 2023-2033.

61. Liu, L.; Wagner, H.D. Rubbery and glassy epoxy resins reinforced with carbon nanotubes. Compos. Sci. Technol. 2005, 65, 1861-1868. [CrossRef]

62. Wagner, H.D.; Lourie, O.; Feldman, Y.; Tenne, R. Stress induced fragmentation of multiwall carbon nanotubes in a polymer matrix. Appl. Phys. Lett. 1998, 72, 188-190. [CrossRef]

63. Wang, X.; Chung, D.D.L. Real-time monitoring of fatigue damage and dynamic strain in carbon fibre-matrix composite by electrical resistance measurement. Smart Mater. Struct. 1997, 6, 504-508. [CrossRef]

64. Tripathi, K.M.; Vincent, F.; Castro, M.; Feller, J.F. Flax fibres-epoxy with embedded nanocomposite sensors to design lightweight smart bio-composites. Nanocomposites 2016, 2, 125-134. [CrossRef]

65. Zhang, X.W.; Pan, Y.; Zheng, Q.; Yi, W.S. Time dependence of piezoresistance for the conductor-filled polymer composites. J. Polym. Sci. B 2000, 38, 2739-2749. [CrossRef]

66. Knite, M.; Tupureina, V.; Fuith, A.; Zavickis, J.; Teteris, V. Polyisoprene-multi-wall carbon nanotube composites for strain sensing. Mater. Sci. Eng. C 2007, 27, 1125-1128. [CrossRef]

67. Takeda, T.; Shindo, Y.; Kuronuma, Y.; Narita, F. Modeling and characterization of the electrical conductivity of carbon nanotube-based polymer composites. Polymer 2011, 52, 3852-3856. [CrossRef]

68. Thostenson, E.T.; Chou, T.W. Processing-structure-multi-functional property relationship in carbon nanotube/epoxy composites. Carbon 2006, 44, 3022-3029. [CrossRef]

69. EPOLAM 2020 Datasheet. Available online: https://advanced-resins.sika.com/en/solutions_products/ product-groups/composite-resin-systems/composite-resin-systems-for-hand-lay-up/epolam-2020.html (accessed on 29 November 2017).

70. Seyhan, A.T.; Tanoglu, M.; Schulte, K. Mode I and mode II fracture toughness of E-glass non crimp fabric carbon nanotube (CNT) modified polymer based composites. Eng. Fract. Mech. 2008, 75, 5151-5162. [CrossRef]

71. Penudamu, D.; Dutta, A.; Pharr, G.M.; Files, B. Mechanical properties of blended SWCNT composites. J. Mater. Res. 2003, 18, 1849-1853.

72. Breton, D.; Désarmot, G.; Salvetat, J.P.; Sinturel, C.; Béguin, F.; Bonnamy, S. Mechanical properties of multiwall carbon nanotubes/epoxy composites: Influence of network morphology. Carbon 2004, 42, 1027-1030. [CrossRef] 
73. Nadler, M.; Werner, J.; Mahrolz, T.; Riedel, U.; Hufenbach, W. Effect of CNT surface functionalization on the mechanical properties of multi walled carbon nanotube/epoxy-composites. Composites A 2009, 40, 932-937. [CrossRef]

74. Guo, P.; Chen, X.; Gao, X.; Song, H.; Shen, H. Fabrication and mechanical properties of well-dispersed carbon nanotubes/epoxy composites. Compos. Sci. Technol. 2007, 40, 3331-3337. [CrossRef]

75. Xiao, K.Q.; Zhang, L.C. The stress transfer efficiency of a single-walled carbon nanotube in epoxy matrix. J. Mater. Sci. 2004, 39, 4481-4486. [CrossRef]

76. Fiedler, B.; Gojny, F.H.; Wichmann MH, G.; Nolte MC, M.; Schulte, K. Fundamental aspects of nano-reinforced composites. Compos. Sci. Technol. 2005, 66, 3115-3125. [CrossRef]

77. Godara, A.; Mezzo, L.; Luizi, F.; Warrier, A.; Lomov, S.V.; Van Vuure, A.W.; Gorbatikh, L.; Moldenaers, P. Verpoest I, Influence of carbon nanotube reinforcement on the processing and the mechanical behaviour of carbon fibre/epoxy composites. Carbon 2009, 47, 2914-2923. [CrossRef]

78. Jar, P.Y.; Davies, P. Matrix effect on the static and dynamic interlaminar fracture toughness of glass-fibre marine composites. Composites B 1998, 29, 505-516.

79. Albertsen, H.; Ivens, J.; Peters, P.; Wevers, M.; Verpoest, I. Interlaminar fracture toughness of CFRP influenced by fibre surface treatment: Part 1 experimental results. Compos. Sci. Technol. 1995, 54, 133-145. [CrossRef]

80. Jang, J.; Shin, S. Toughness improvement of tetrafunctional epoxy resin by using hydrolysed poly(ether imide). Polymer 1995, 36, 1199-1207. [CrossRef]

81. Verrey, J.; Winkler, Y.; Michaud, V.; Manson, J.A.E. Interlaminar fracture toughness improvement in composites with hyperbranched polymer modified resin. Compos. Sci. Technol. 2005, 65, 1527-1536. [CrossRef]

82. Gao, L.; Chou, T.W.; Thostenson, E.T.; Zuoguang, Z. A comparative study of damage sensing in fibre composites using uniformly and non-uniformly dispersed carbon nanotubes. Carbon 2010, 48, 3788-3794. [CrossRef]

83. Böger, L.; Wichmann MH, G.; Meyer, L.O.; Schulte, K. Load and health monitoring in glass fibre reinforced composites with an electrically conductive nanocomposite epoxy matrix. Compos. Sci. Technol. 2008, 68, 1886-1894. [CrossRef]

84. Seo, D.C.; Lee, J.J. Effect of embedded optical fibre sensors on transverse crack spacing of smart composite structures. Compos. Struct. 1995, 32, 51-58. [CrossRef]

85. Lachman, N.; Bartholome, C.; Miaudet, P.; Maugey, M.; Poulin, P.; Wagner, H.D. Raman response of carbon nanotube/PVA fibres under strain. J. Phys. Chem. C 2009, 113, 4751-4754. [CrossRef]

86. Suzuki, Y.; Ohnishi, M.; Suzuki, K.; Miura, H. Remote non-contact strain sensor using carbon nanotube-dispersed resin. In Proceedings of the Microsystems Packaging Assembly \& Circuits Technology Conference, 2010, 5th International IMPACT, Taipei, Taiwan, 20-22 October 2010.

87. Park, M.; Kim, H.; Youngblood, J.P. Strain-dependent electrical resistance of multiwalled nanotube/polymer composite films. Nanotechnology 2008, 19, 055705. [CrossRef] [PubMed]

88. Bautista-Quijano, J.R.; Avilésa, F.; Aguilara, J.O.; Tapia, A. Strain sensing capabilities of a piezoresistive MWCNT-polysulfone film. Sens. Actuators A Phys. 2010, 159, 135-140. [CrossRef]

(C) 2019 by the authors. Licensee MDPI, Basel, Switzerland. This article is an open access article distributed under the terms and conditions of the Creative Commons Attribution (CC BY) license (http://creativecommons.org/licenses/by/4.0/). 